\title{
Entrelacs
}

ENTRELACS Cinéma et audiovisuel

HS | 2012

Le post-humain et les enjeux du sujet

\section{Les enjeux d'immortalité pour le post-humain, dans la réalité dans le monde virtuel des jeux vidéos}

\section{Somphout Chanhthaboutdy}

\section{(2) OpenEdition \\ Journals}

Édition électronique

URL : http://journals.openedition.org/entrelacs/307

DOI : 10.4000/entrelacs.307

ISSN : 2261-5482

Éditeur

Éditions Téraèdre

Édition imprimée

Date de publication : 2 février 2012

ISBN : 978-2296567177

ISSN : 1266-7188

\section{Référence électronique}

Somphout Chanhthaboutdy, « Les enjeux d'immortalité pour le post-humain, dans la réalité dans le monde virtuel des jeux vidéos », Entrelacs [En ligne], HS | 2012, mis en ligne le 01 août 2012, consulté le 06 mai 2019. URL : http://journals.openedition.org/entrelacs/307 ; DOI : 10.4000/entrelacs.307

Ce document a été généré automatiquement le 6 mai 2019.

Tous droits réservés 


\title{
Les enjeux d'immortalité pour le post-humain, dans la réalité dans le monde virtuel des jeux vidéos
}

\author{
Somphout Chanhthaboutdy
}

1 Le texte complet de cet article est publié dans l'ouvrage :

Post humain et les enjeux du sujet

Editeur : L'HARMATTAN (2 février 2012)

Collection Ouverture Philosophique

ISBN-10 : 2296567177

ISBN-13 : 978-229656717

\section{RÉSUMÉS}

Les actions post-humanistes concernant la transformation du corps humain, en une sorte de corps version 2.0 composé d'éléments naturels et artificiels, conduiraient comme le dit Ray Kurzweil à modifier complètement la biologie de l'espèce. Pour certains, cette modification aurait un but artistique dans la recherche de nouveau média d'expression, pour d'autres cela représenterait un espoir pour atteindre l'immortalité. Le mouvement transhumaniste, qui défend le droit à la vie éternelle grâce aux technologies de prolongation, représente bien cet enjeu d'immortalité dans une société tournée vers la biomédicalisation.

En parallèle à ce monde biomédical où l'on recherche l'immortalité par la transformation réelle du corps vers la fusion homme/machine, se trouve le monde virtuel des jeux vidéo. Dans les jeux en ligne que l'on nomme FPS « first person shooting », ou MMO « massively multiplayer online », le joueur prend du plaisir à tuer l'autre. Or, la question dans ces jeux n'est pas la prise de plaisir dans la sensation ultime de pouvoir tuer sans contrepartie. Mais le problème réside 
essentiellement dans la possibilité d'être immortel dans ces jeux.

Devant un tel engouement, les jeux vidéo FPS et MMO ne seraient-ils pas la porte vers la projection virtuelle d'un humain 1.5 évolué ? La société post-modern ne serait-elle pas en train de préparer ses futurs post-humains de demain, grâce à ces jeux ? N'y aurait-il pas, une espèce de grand mythe de l'immortalité dans les jeux vidéo comme dans le courant post-humaniste ? Car les enjeux pour toutes ces personnes qu'elles soient âgées ou jeunes, réelles ou virtuelles, sont de repousser les limites de la mort, pour vivre et découvrir dans un premier temps l'amortalité, puis dans un second temps si la science le permet, l'immortalité.

\section{AUTEUR}

\section{SOMPHOUT CHANHTHABOUTDY}

ATI INREV, Université PARIS 8 